\section{Research please}

Sir, in spring 2020, Public Health England evaluated the presence of air-borne SARSCoV-2 as part of a wider investigation into environmental contamination within hospital settings where COVID patients were being treated. ${ }^{1}$ The authors reported detectable levels of virus in $7.3 \%$ of air samples. This study confirms the depth of research capability within the UK scientific community.

It is unclear to us why similar investigations have not taken place in dentistry. It would be important to assess the actual risk of air-borne SARS-CoV-2 transmission in dental practices. These findings may have very significant implications for the prospect of stepping-down current precautionary measures.

Efforts have been made to count airborne particles generated within the dental environment under differing experimental conditions. However, the clinical relevance of counting particles of indeterminate composition remains equivocal. The NHS has previously funded research into dental bio-aerosol. ${ }^{2,3}$ This was carried out by the Centre of Applied Microbiology \& Research - a precursor constituent of Public Health England. We are unsure as to the motivation for the NHS to conduct research into dental bio-aerosol 20 years ago. Equally perplexing are reasons why this fleeting curiosity diminished as quickly as it appeared.
We invite our more learned colleagues to direct us to existing or in-progress studies which seek to resolve the outstanding question of the risks associated with dental treatment during a pandemic.

R. Vasant, A. Haigh, London, UK

\section{References}

1. Moore G, Rickard H, Stevenson D et al. Detection of SARSCoV-2 within the healthcare environment: a multicentre study conducted during the first wave of the COVID-19 outbreak in England. J Hosp Infect 2021; 108: 189-196.

2. Bennett A M, Fulford M R, Walker J T, Bradshaw D J, Martin M V, Marsh P D. Microbial aerosols in general dental practice. BrDent J 2000; 189: 664-667

3. Private correspondence between $R$ Vasant and $A$ Bennett. 2020.

https://doi.org/10.1038/s41415-021-2748-y

\section{Oral health}

\section{Is sexual history important?}

Sir, oral candidiasis (OC) is the most common opportunistic infection seen in patients infected with human immunodeficiency virus (HIV). ${ }^{1,2}$ Where OC does not respond to local measures and appropriate drug regimens, or there is no identifiable cause, this is when underlying causes such as HIV should be considered. This makes sexual history an essential part of the history taking process, and potentially a vital piece of the diagnostic puzzle. A recent case of a 70-year-old male who was referred by his GP to our oral and maxillofacial surgery (OMFS) department with refractory OC and was then later diagnosed with HIV has prompted this letter.

The authors do not advocate HIV testing for every patient who walks into the clinic with OC, but rather recommend that in cases of refractory OC, where appropriate, a sexual history be taken. This will prove vital to the clinician in deciding whether a referral to a specialist ie local OMFS department, or the patient's GP for further investigation is required.

Often there are social barriers to taking a sexual history which include time constraints, fear of patient embarrassment, fear of intrusion, insufficient training, age and sex of patient relative to that of the practitioner and cultural difference. ${ }^{3}$ Often, it is useful to pre-empt the patient's potential discomfort by initially informing them that they will be asked personal, and often embarrassing, questions. ${ }^{4}$

OC may be the first presentation of an occult disease, ${ }^{5}$ and still remains the second
AIDS-defining illness in Europe. Therefore, in refractory cases or where there is no identifiable cause, dentists should use an appropriate sexual history combined with a thorough medical and social history. This plays a vital role in determining if HIV screening is necessary and overall provides the firm basis for gaining information regarding the patient's risk status in an environment where the patient is assured of the maintenance of privacy and confidentiality.

S. Duggal, C. Wanis, V. Oktseloglou, Bradford, UK

\section{References}

1. Powderly W G, Mayer K H, Perfect J R. Diagnosis and treatment of oropharyngeal candidiasis in patients infected with HIV: a critical reassessment. AIDS Res Hum Retroviruses 1999; 15: 1405-1412

2. Anwar KP, Malik A, Subhan K H. Profile of candidiasis in HIV infected patients. Iran J Microbiol 2012; 4: 204-209.

3. Temple-Smith M J, Mulvey G, Keogh L. Attitudes to taking a sexual history in general practice in Victoria, Australia. Sex Transm Infect 1999; 75: 41-44.

4. Jones R, Barton S. Introduction to history taking and principles of sexual health. Postgrad Med J 2004; 8 : 444-446.

5. Aškinytė D, Matulionyte R, Rimkevičius A. Oral manifestations of HIV disease: A review. Stomatologija 2015; 17: 21-28.

https://doi.org/10.1038/s41415-021-2749-x

\section{Facial aesthetics}

\section{Jaw dropping}

Sir, we wish to highlight a trend noticed in patients after improved facial aesthetics. Jawzrsize is advertised as a face and neck toning' device but in our opinion it could potentially cause negative effects for patients looking for a more square, prominent jaw. The device is effectively a rubber ball with or without upper and lower occlusal rests for the incisal teeth; these can be 'custom fit' akin to 'boil and bite' mouth guards. The consumer then bites up and down on the device for numerous repetitions and sets as they see fit throughout the day. The resistance of the devices ranges from 20 to $40 \mathrm{lbs}$ ( 89 to $178 \mathrm{~N}$ ). The average range of force exerted when eating carrots or meat is 70 to $150 \mathrm{~N} .^{1}$

The website for the device has numerous claims without any medical backing including improved collagen stimulation, improved jaw function and relief of TMJD symptoms. It seems likely that the repeated use of this device will result in far more stresses on the TMJ and cause significant wear on the articular disc potentially triggering various TMJD symptoms from crepitus to complete dislocation. The effort exerted by use of this device could be compared to those of bruxists and could lead patients down the path of requiring neuromodulators to reduce the muscle activity of the masseter.

Healthy jaw rehabilitation emphasises gentle conditioning not inducing extreme stresses. Following a routine of simple resistance exercises with your own hands is regarded as a useful tool in conservative management of TMJD. ${ }^{2}$

T. Nagpal, A. Gupta, London, UK

\section{References}

1. Anderson D J. Measurement of stress in mastication. I. J Dent Res 1956; 35: 664-670.

2. Calixtre L B, Moreira R F, Franchini G H, AlburquerqueSendín F, Oliveira A B. Manual therapy for the management of pain and limited range of motion in subjects with signs and symptoms of temporomandibular disorder: a systematic review of randomised controlled trials. J Oral Rehabil 2015; 42: 847-861.

https://doi.org/10.1038/s41415-021-2750-4 